\title{
An Early Screening Tool for Discharge Planning Shortened Length of Hospital Stay for Elderly Patients with Community-Acquired Pneumonia
}

This article was published in the following Dove Press journal:

Clinical Interventions in Aging

\author{
Hao Chen' \\ Yu Hara' \\ Nobuyuki Horita' \\ Yusuke Saigusa ${ }^{2}$ \\ Takeshi Kaneko' \\ 'Department of Pulmonology, Yokohama \\ City University Graduate School of \\ Medicine, Yokohama, Japan; ${ }^{2}$ Department \\ of Biostatistics, Yokohama City University \\ Graduate School of Medicine, Yokohama, \\ Japan
}

Background: Community-acquired pneumonia is one of the most common diseases in elderly persons and usually results in a prolonged hospital stay. Discharge planning plays an important role in reducing the length of hospitalization. This study was designed to determine whether early screening for risk factors for delayed discharge could improve the quality of discharge planning.

Methods: This retrospective, observational study was conducted in two medical facilities from January 2016 to December 2018. Hospital A used a screening tool on admission (screening group): screening for risk factors for delayed discharge and initiating discharge planning immediately for those for whom it was applicable, and discharge planning in the stable phase for those for whom it was not applicable; and Hospital B initiated discharge planning without screening (usual group). Propensity score-matched pneumonia patients in the two groups were then compared. The primary outcome was length of hospital stay.

Results: A total of 648 patients were enrolled in this study. After adjusting for age, sex, aspiration, comorbidity, pneumonia severity index, and key person, 118 pairs underwent analysis. Length of stay was significantly different (20 days vs 13 days, $\mathrm{p}<0.001)$ between the groups. There were no differences in duration of antibiotic treatment, in-hospital mortality, and 30-day readmission (9 days vs 9 days, $p=0.744 ; 10$ (8.5\%) vs 10 (8.5\%), p=1.000; $10(8.5 \%)$ vs $9(7.6 \%), \mathrm{p}=0.811$, respectively).

Conclusion: Early screening for delayed discharge improved the quality of discharge planning by reducing the length of stay in pneumonia patients.

Keywords: discharge planning, community-acquired pneumonia, delayed discharge

\section{Introduction}

People worldwide are living longer, and the proportion of the world's population over 60 years of age is predicted to nearly double by 2050 . The aging of populations around the world has been associated with increases in morbidity and mortality attributable to lung diseases. ${ }^{1}$ The annual incidence of community-acquired pneumonia (CAP) in the United States has recently been estimated as 248 cases per 10,000 adults. $^{2}$

Most patients who die from pneumonia are elderly, whereas surviving patients face the additional problem of decreased functional status. Functional decline may lead to an increased need for services, lower levels of autonomy, readmission to hospital, or nursing care facility admission. ${ }^{3}$ Approximately one-fifth of all hospital discharges are delayed for non-medical reasons such as complex social needs,
Correspondence: Hao Chen

Department of Pulmonology, Yokohama

City University Graduate School of

Medicine, 3-9 Fukuura, Kanazawa,

Yokohama, 236-0004, Japan

Tel +8I 045-352-7962

Fax $+81045-352-7963$

Email chinsmd@gmail.com 
preparation of applications for facility placement, and discharge destination planning. ${ }^{4}$ Discharge planning (DP) promotes safe and timely transfer of patients between levels of care and across care settings, especially during patient discharge from a hospital or skilled-nursing facility to a home or community setting, decreasing length of stay (LOS) and hospital readmission. ${ }^{5,6}$

A discharge plan should usually be developed by a registered nurse $(\mathrm{RN})$, social worker, or other appropriately qualified personnel, and it should be initiated as soon as possible after admission. The high workloads of RNs impede timely and secure DP. ${ }^{7}$ The patient's discharge destination plays an important role in increased LOS, since DP for facility placement can require more planning and coordination by hospital staff than a discharge directly home. ${ }^{8}$ This study was designed to determine whether early screening for risk factors for delayed discharge could improve the quality of DP in pneumonia patients.

\section{Materials and Methods}

This was a retrospective, observational study of inpatients admitted to a community-based hospital and a teaching hospital in Japan from January 2015 to December 2018. This study was approved by the institutional review boards of Yokohama City University and Kanto Rosai Hospital (reference numbers: B190600008 and KR2018002, respectively) and conformed to the provisions of the Declaration of Helsinki (as revised in Brazil 2013). Written, informed consent was obtained from participants before starting the study.

Patients in the two hospitals were enrolled in this study. In Hospital A, a screening tool for risk factors for delayed discharge was used on admission. DP was initiated immediately for those who were at risk of delayed discharge, with DP in stable condition for patients without a risk of delayed discharge; this was the screening group. In Hospital B, DP was performed without screening; this was the usual group. Most DPs in the two hospitals were initiated soon after admission.

The screening tool for risk factors for delayed discharge is shown in Figure 1. There were 23 minor items for the major items 1 to 6 and 7 minor items for major items 7 to 8 . Patients with 3 or more minor items that were from major items 1 to 6 , or even only 1 minor item from major items 7 to 8 were identified as at risk of delayed discharge.

\section{Patients}

All enrolled cases had been diagnosed with CAP according to the definitions of the American Thoracic Society/ Infectious Diseases Society of America guideline. ${ }^{9}$ Patients who fulfilled all of the following inclusion criteria were enrolled in the study: 1) age $>64$ years; 2) symptoms compatible with pneumonia (eg, fever, cough, sputum, pleuritic chest pain, or dyspnea); and 3) appearance of new pulmonary infiltrates consistent with pneumonia on chest X-ray or computed tomography. To ensure that all eligible cases were enrolled, the study investigators screened the hospital database for International Classification of Diseases, 10th revision (ICD-10) codes and reviewed hospital medical records. Cases of healthcare-associated pneumonia (HCAP) and hospital-acquired pneumonia (HAP) were excluded. ${ }^{10}$

A total of 1866 patients diagnosed with pneumonia were identified. Of these, the following were excluded: 278 due to age $<65$ years; 612 due to outpatient treatment; 113 due to HCAP or HAP; and 203 due to incomplete data. Of the 648 cases, 118 matched pairs in two groups were included in the study after propensity score matching based on age, sex, aspiration, CCI, PSI, and key person (Figure 2).

\section{Outcomes}

The primary outcome was the LOS. Demographic information, comorbidities, pneumonia severity index (PSI), ${ }^{11}$ duration of antibacterial treatment, waiting duration (duration between the end of antibacterial treatment and discharge), inhospital mortality, site of acquisition for survivors, and allcause 30-day readmission in the same hospital were also collected. Comorbidities were identified according to the Charlson Comorbidity Index (CCI). ${ }^{12}$ The PSI score was calculated based on data obtained at the time of admission.

\section{Statistical Analyses}

The results are presented as numbers and percentages or medians and interquartile ranges unless otherwise indicated. Groups were compared using Wilcoxon rank-sum tests. In order to reduce bias affecting LOS, population demographics and characteristics of patients in the two hospitals were compared. Propensity score matching was performed for age, sex, aspiration, CCI, PSI, and key person in order that the standardized differences of all matching factors be less than 0.25 in the matched pairs. ${ }^{13}$ The effect of DP was analyzed in propensity scorematched pairs by adjusting for age, sex, aspiration, CCI, 


\begin{tabular}{|c|c|c|c|}
\hline Major items & \multicolumn{3}{|c|}{ Minor items } \\
\hline $\begin{array}{l}\text { 1. Disease/medical } \\
\text { condition }\end{array}$ & [ & \multicolumn{2}{|c|}{$\begin{array}{l}\text { Terminal stage of malignant disease } \\
\text { Acute respiratory infections such as aspiration pneumonia } \\
\text { Dementia } \\
\text { Cerebrovascular disease } \\
\text { Diseases/conditions that result in ADL decline or continuous } \\
\text { medical treatment }\end{array}$} \\
\hline 2. Hospitalization & & \multicolumn{2}{|c|}{$\begin{array}{l}\text { Readmission within } 1 \text { month } \\
\text { Unplanned admission }\end{array}$} \\
\hline 3. Family structure & $\square$ & \multicolumn{2}{|c|}{$\begin{array}{l}\text { Living alone } \\
\text { Households of older couples (generally, over } 75 \text { years of age) }\end{array}$} \\
\hline $\begin{array}{l}\text { 4. Activities of daily } \\
\text { living }\end{array}$ & $\square$ & \multicolumn{2}{|c|}{$\begin{array}{l}\text { Nursing or support will be required at discharge } \\
\text { Insufficient self-care }\end{array}$} \\
\hline $\begin{array}{l}\text { 5. Nursing status at } \\
\text { home }\end{array}$ & $\begin{array}{l}\square \\
\square\end{array}$ & \multicolumn{2}{|c|}{$\begin{array}{l}\text { Care services necessary but not applied } \\
\text { No caregiver } \\
\text { Caregivers fatigued, or no desire to care } \\
\text { Caregivers' care skill was inadequate } \\
\text { Home visit doctor/nursing is required }\end{array}$} \\
\hline $\begin{array}{l}\text { 6. Continued } \\
\text { medical treatment } \\
\text { required }\end{array}$ & $\square$ & $\begin{array}{l}\text { Ventilator } \\
\text { Tracheostomy } \\
\text { Self-injection }\end{array}$ & $\begin{array}{l}\square \text { Parenteral nutrition } \\
\square \text { Home oxygen therapy } \\
\square \text { Tube feeding }\end{array}$ \\
\hline $\begin{array}{l}\text { 7. Economic } \\
\text { situation }\end{array}$ & & \multicolumn{2}{|c|}{$\begin{array}{l}\text { Uninsured } \\
\text { Worried about paying medical expenses } \\
\text { Worried about living expenses }\end{array}$} \\
\hline 8. Social issues & & $\begin{array}{l}\text { Child/elderly abuse } \\
\text { Absence of discharge } \\
\text { destination }\end{array}$ & $\begin{array}{l}\square \text { Unspecified address } \\
\square \text { Absence of key person }\end{array}$ \\
\hline
\end{tabular}

Figure I Checklist of risk factors for delayed discharge.

Note: Early discharge planning performed if 3 or more minor items from major items 1 to 6 were applicable, or even I minor item from major items 7 to 8.

Abbreviation: ADL, activities of daily living.

PSI, and key person. In all instances, two-tailed values of $\mathrm{p}<0.05$ were considered significant. Data analysis was performed using JMP software (version 15.0; SAS Institute, Cary, NC).

\section{Results}

Before matching, the participants were 433 men (64.8\%) and 215 women (35.2\%), with a median age of 76 years (68-83 years), as shown in Table 1. The background 


\section{Pneumonia patients $(n=1854)$}

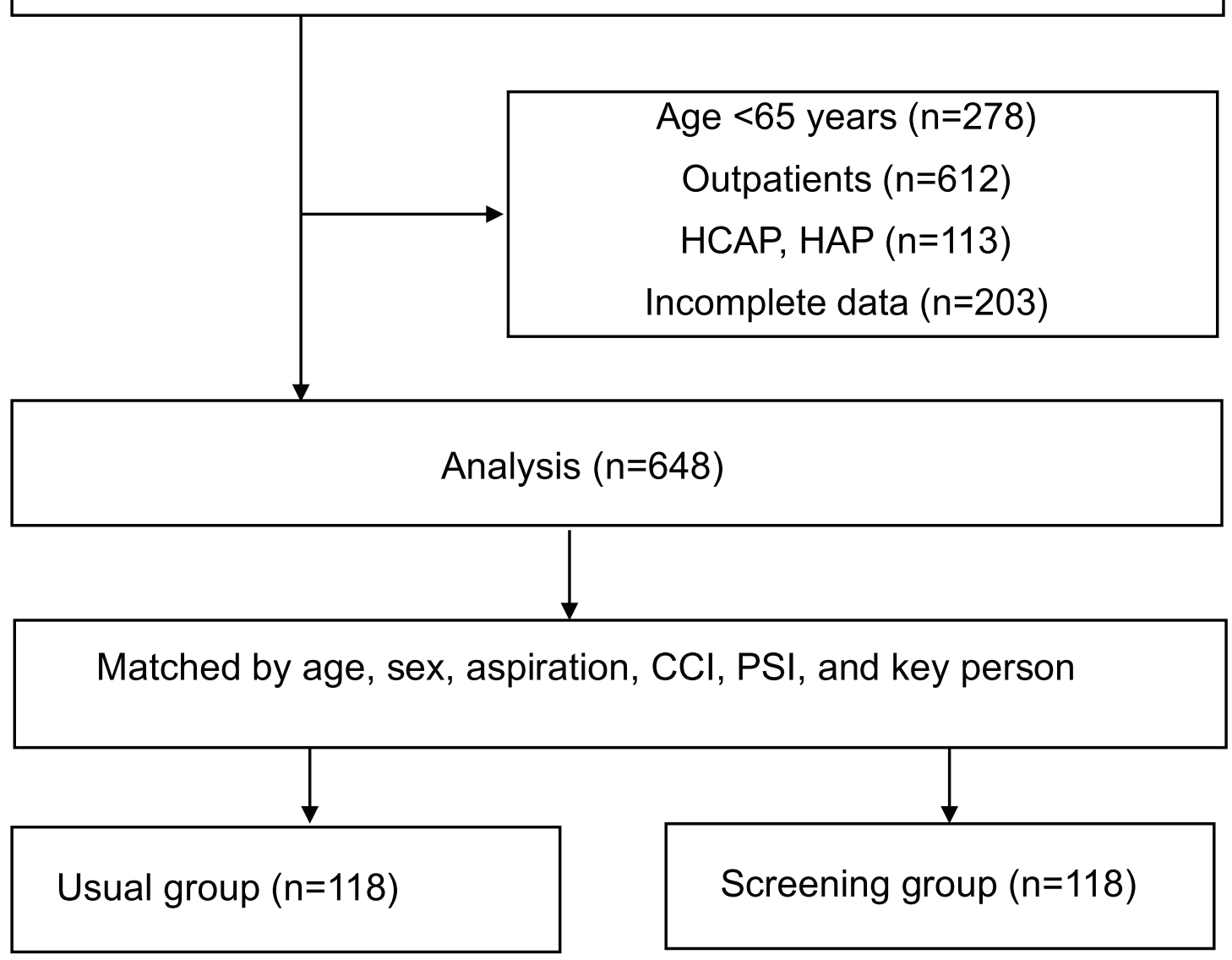

Figure 2 Flowchart of the study.

Abbreviations: HCAP, healthcare-associated pneumonia; HAP, hospital-acquired pneumonia; CAP, community-acquired pneumonia.

characteristics of these patients are summarized in Table 1. Age, aspiration, rate of enrollment in rehabilitation, CCI, PSI, and key person were significantly different. Sex, BMI, and dementia were not significantly different between the two hospitals. Patients in hospital B were younger than patients in hospital A, but patients in hospital A had higher categories of CCI and PSI and, thus, higher hospital mortality ( $5.2 \%$ vs $10.8 \%$, respectively; $\mathrm{p}<0.001)$.

Detailed information for the matched pairs is shown in Table 2. The standardized difference of all variables was less than 0.25 , and matching was considered to be effective. LOS was longer in the usual group than in the screening group (19.5 days vs 13 days, respectively; $p<0.001$ ). The duration of antibacterial treatment ( 9 days vs 9 days, respectively; $\mathrm{p}=0.744)$ and in-hospital mortality ( $8.5 \%$ vs $8.5 \%$ respectively; $p=1$ ) showed no significant differences between the two groups. Among survivors, patients showed a high rate of discharge home in the screening group $(57.4 \%$ vs $63.9 \%$, respectively; $\mathrm{p}<0.001$, overall). The screening group showed lower medical costs due to reduced LOS ( $\$ 5476$ vs $\$ 4985$, respectively; $\mathrm{p}=0.035$ ). The all-cause 30 -day readmission rate was not significantly different $(8.5 \%$ vs $7.6 \%$, respectively; $\mathrm{p}=0.811)$. There were $77(65.2 \%)$ patients at risk of delayed discharge, and most of them were due to acute respiratory infections, unplanned admission, and households of older couples.

The wait times between end of antibacterial treatment and discharge to different destinations are shown in Table 3. The wait times for discharge to home, nursing home, facility, and hospital were significantly different between the two groups ( 8 vs 2,9 vs 4,30 vs 9 , and 35 vs 11 , respectively, $\mathrm{p}<0.001$, each).

\section{Discussion}

In this retrospective, case-controlled trial, LOS was significantly lower when a screening tool for DP was used on 
Table I Population Demographics, Characteristics, and Outcomes of the Two Groups

\begin{tabular}{|c|c|c|c|c|}
\hline & Total & Usual Group & Screening Group & \\
\hline & $n=648$ & $n=325$ & $n=323$ & p-value \\
\hline Age (y) & $76(68-83)$ & 79 (7I-84) & $73(66-8 I)$ & $<0.001$ \\
\hline Male/Female & $433 / 215$ & $1113 / 212$ & $102 / 221$ & 0.389 \\
\hline BMI & $19.3(16.6-22.3)$ & $18.7(\mid 6.5-22.1)$ & $19.6(16.9-22.4)$ & 0.220 \\
\hline Dementia & 71 (11.0\%) & $41(6.3 \%)$ & $30(4.6 \%)$ & 0.175 \\
\hline Bedsore & $16(2.5 \%)$ & $6(0.9 \%)$ & $10(1.5 \%)$ & 0.305 \\
\hline Aspiration & 135 (20.8\%) & 38 (5.9\%) & 97 (I5.0\%) & $<0.001$ \\
\hline CCl score & & & & $<0.001$ \\
\hline$\leq 1$ & 198 (30.6\%) & 135 (4I.5\%) & 63 (19.5\%) & \\
\hline 2 & 191 (29.5\%) & $100(30.8 \%)$ & 91 (28.2\%) & \\
\hline$\geq 3$ & 259 (40.0\%) & 90 (27.7\%) & 169 (52.3\%) & \\
\hline PSI category & & & & $<0.001$ \\
\hline II & 57 (8.8\%) & 38 (II.7\%) & 19 (5.9\%) & \\
\hline III & $128(19.8 \%)$ & 107 (32.9\%) & $21(6.5 \%)$ & \\
\hline IV & $259(40.0 \%)$ & 143 (44.0\%) & $116(35.9 \%)$ & \\
\hline$\vee$ & 204 (31.5\%) & 37 (II.4\%) & 167 (5I.7\%) & \\
\hline DOAT & $9(7-12)$ & $8(7-12)$ & $9(7-13)$ & 0.135 \\
\hline LOS & $15(9-24)$ & $16(10-27.5)$ & $13(9-22)$ & $<0.001$ \\
\hline Survived & & & & 0.011 \\
\hline At home & 381 (63.9\%) & $198(64.3 \%)$ & $183(63.5 \%)$ & \\
\hline Nursing home & $121(22.3 \%)$ & $74(24.0)$ & 47 (16.3\%) & \\
\hline Facility & $50(8.4 \%)$ & $19(6.2 \%)$ & 31 (10.8\%) & \\
\hline Hospital & $44(7.4 \%)$ & 17 (5.5\%) & 27 (9.4\%) & \\
\hline In-hospital mortality & $52(8.0 \%)$ & 17 (5.2\%) & $35(10.8)$ & 0.009 \\
\hline Key person & & & & $<0.001$ \\
\hline Children & $250(38.6 \%)$ & 167 (5I.4\%) & $83(25.8 \%)$ & \\
\hline Spouse & $324(50.1 \%)$ & 127 (39.1\%) & 197 (6I.2\%) & \\
\hline Others & 73 (II.3\%) & $31(9.5 \%)$ & $42(13.0 \%)$ & \\
\hline
\end{tabular}

Abbreviations: BMI, body mass index; CCl, Charlson Comorbidity Index; DOAT, duration of antibiotic treatment; LOS, length of stay; PSI, Pneumonia Severity Index.

admission, whereas duration of antibacterial treatment and in-hospital mortality were not significantly different between the two groups. After propensity score matching, the differences in background characteristics, treatments, and outcomes of CAP patients between the two groups were almost eliminated, and the reduction of LOS in the screening group seemed reliable. This finding was consistent with previous studies showing that DP started at the beginning of hospitalization plays a key role in increasing efficiency and improving quality of life for vulnerable elderly persons needing continuity of care. ${ }^{14,15}$
Patients in the screening group had an increased rate of discharge home overall, without an increased rate of all-cause 30-day readmission. One high-quality way to deal with the demand for hospital beds is to reduce LOS by discharging people early to receive health care at home with lower rates of 30-day hospital readmission. ${ }^{16,17}$ Using a screening tool for DP might be an effective tool to meet the two demands of reduced LOS and a low readmission rate as usual DP. Wait times were shorter in the screening group than in the usual group for all 4 categories of discharge destinations. Improving hospital patient flow is important to optimize the use of limited 
Table 2 Matched Pairs in the Two Groups

\begin{tabular}{|c|c|c|c|c|}
\hline & $\begin{array}{l}\text { Usual } \\
\text { Group }\end{array}$ & $\begin{array}{l}\text { Screening } \\
\text { Group }\end{array}$ & p-value & Std-Diff \\
\hline & $n=118$ & $n=118$ & & \\
\hline Age (y) & $79(70-83)$ & $76.5(67-84)$ & 0.268 & 0.145 \\
\hline Male/Female & $87 / 31$ & $75 / 43$ & 0.092 & 0.219 \\
\hline Aspiration & $24(20.3 \%)$ & $25(21.2 \%)$ & 0.873 & 0.021 \\
\hline $\mathrm{CCl}$ & & & 0.161 & \\
\hline$\leq 1$ & 42 (35.6\%) & $45(38.1 \%)$ & & 0.052 \\
\hline 2 & 27 (22.9\%) & $37(31.4 \%)$ & & 0.192 \\
\hline$\geq 3$ & $49(41.5 \%)$ & $36(30.5 \%)$ & & 0.231 \\
\hline PSI score & & & 0.175 & \\
\hline II & $6(5.1 \%)$ & $12(10.2 \%)$ & & 0.193 \\
\hline III & 14 (11.9\%) & $17(14.4 \%)$ & & 0.074 \\
\hline IV & 66 (55.9\%) & 53 (44.9\%) & & 0.221 \\
\hline v & $32(27.1 \%)$ & $36(30.5 \%)$ & & 0.075 \\
\hline Key person & & & 0.971 & \\
\hline Children & 46 (39.0\%) & 47 (39.8\%) & & 0.016 \\
\hline Spouse & 61 (51.7\%) & $61(51.7 \%)$ & & 0 \\
\hline Others & II (9.3\%) & $10(8.5 \%)$ & & 0.028 \\
\hline LOAT (day) & $9(7-14)$ & $9(6-12)$ & 0.744 & 0.043 \\
\hline LOS (day) & $19.5(11-32)$ & $13(8-22)$ & $<0.001$ & 0.410 \\
\hline Survived & & & 0.011 & \\
\hline At home & 62 (57.4\%) & 69 (63.9\%) & & 0.133 \\
\hline Nursing home & $35(32.4 \%)$ & $17(15.7 \%)$ & & 0.398 \\
\hline Facility & $4(3.7 \%)$ & $12(11.1 \%)$ & & 0.286 \\
\hline Hospital & $7(6.5 \%)$ & $10(9.3 \%)$ & & 0.104 \\
\hline $\begin{array}{l}\text { In-hospital } \\
\text { mortality }\end{array}$ & $10(8.5 \%)$ & $10(8.5 \%)$ & 1.000 & 0 \\
\hline Readmission & $10(8.5 \%)$ & $9(7.6 \%)$ & 0.811 & 0.033 \\
\hline Early discharge & $\begin{array}{c}\text { Not } \\
\text { applicable }\end{array}$ & 77 (65.2\%) & & \\
\hline Cost (\$) & $\begin{array}{c}5476 \\
(3830-8299)\end{array}$ & $\begin{array}{c}4985 \\
(3542-7295)\end{array}$ & 0.035 & 0.282 \\
\hline
\end{tabular}

Abbreviations: $\mathrm{CCl}$, Charlson Comorbidity Index; LOAT, length of antibiotic treatment; LOS, length of stay; PSI, Pneumonia Severity Index; std-diff, standardized difference.

healthcare resources efficiently and minimize iatrogenic adverse events, and it may ensure patient-centered care. ${ }^{18}$ A screening tool for DP would make the transition of care from the hospital to the next destination more effective.

Immediate DP was initiated in about $65 \%$ of patients in the screening group with risk factors for delayed discharge. Focusing on these patients could make DP more effective than initiating DP for all patients at admission. Patients without a risk of delayed discharge underwent DP in a stable
Table 3 Details of Waiting Time After Antibacterial Treatment for Different Discharge Destinations

\begin{tabular}{|l|l|l|l|}
\hline & $\begin{array}{l}\text { Usual } \\
\text { Group }\end{array}$ & $\begin{array}{l}\text { Screening } \\
\text { Group }\end{array}$ & p value \\
\hline Home (day) & $8(3-15)$ & $2(I-5)$ & $<0.00$ I \\
Nursing home (day) & $9(2-17)$ & $4(2-10)$ & $<0.00$ I \\
Facility (day) & $30(7-23)$ & $9(I-23)$ & $<0.00$ I \\
Hospital (day) & $35(12-59)$ & II (2-24) & $<0.00$ I \\
Overall (day) & $9(2-17)$ & $2(I-9)$ & $<0.00$ I \\
\hline
\end{tabular}

condition. This could reduce the burden of nurses doing all of the work at one time on admission, since nursing is a stressful occupation, especially with increasing amounts of overtime. ${ }^{19,20}$ It is important to focus on the work environment of nurses to improve their job satisfaction and retention, and thereby decrease healthcare costs by increasing efficiency. ${ }^{21}$

\section{Limitations}

Some limitations to this study need to be considered when interpreting the present results. First, this study was carried out in two different medical facilities, because data of patients before and after screening tests in the same hospital were not available. The manpower or the surrounding situation varied across the facilities, and the quality of DP might differ in the two facilities. Although one-to-one propensity score matching analysis was used to reduce bias in the two hospitals, processing missing data may have reduced the number of eligible patients in the study and may have led to selection bias. Second, only CAP patients were included, and DP for HCAP or HAP is also important for elderly patients, but it was not examined. Third, there were other factors that could affect DP that were not included in this study, such as exercise, social issues, and economic situation. Fourth, the sensitivity and specificity of screening tools for delayed discharge were not evaluated.

\section{Conclusions}

Early screening for delayed discharge could improve the quality of DP by reducing LOS in pneumonia patients.

\section{Abbreviations}

CAP, community-acquired pneumonia; DP, Discharge planning; RN, registered nurse; ICD-10, International Classification of Diseases, 10th revision; HCAP, healthcareassociated pneumonia; HAP, hospital-acquired pneumonia; CCI, Charlson Comorbidity Index; PSI, Pneumonia Severity 
index; DOC, disorder of consciousness; BMI, body mass index; CI, confidence interval.

\section{Data Sharing Statement}

The raw data are available by email on reasonable request to the corresponding author.

\section{Ethics Approval and Consent to Participate}

Ethical approval for the study was obtained from the institutional review boards of Yokohama City University and Kanto Rosai Hospital (reference numbers B190600008 and K2018002, respectively).

\section{Acknowledgments}

The authors would like to thank and acknowledge the cooperation of all of the participants in the study who volunteered their time and gave accounts of experiences without which none of the work would have been possible.

\section{Author Contributions}

All authors made a significant contribution to the work reported, whether that is in the conception, study design, execution, acquisition of data, analysis and interpretation, or in all these areas; took part in drafting, revising or critically reviewing the article; gave final approval of the version to be published; have agreed on the journal to which the article has been submitted; and agree to be accountable for all aspects of the work.

\section{Funding}

There is no funding to report.

\section{Disclosure}

The authors declare that they have no competing interests.

\section{References}

1. Cho SJ, Stout-Delgado HW. Aging and lung disease. Annu Rev Physiol. 2020;82(1):433-459. doi:10.1146/annurev-physiol-021119034610

2. Jain S, Self WH, Wunderink RG, et al. Community-acquired pneumonia requiring hospitalization among U.S. adults. $N$ Engl $J$ Med. 2015;373(5):415-427. doi:10.1056/NEJMoa1500245

3. Wales K, Clemson L, Lannin NA, et al. Occupational therapy discharge planning for older adults: a protocol for a randomised trial and economic evaluation. BMC Geriatr. 2012;12(1):34. doi:10.1186/14712318-12-34

4. McDonagh MS, Smith DH, Goddard M. Measuring appropriate use of acute beds A systematic review of methods and results. Health Policy (New York). 2000;53:157-184. doi:10.1016/s0168-8510(00)00092-0
5. Rodakowski J, Rocco PB, Ortiz M, et al. Caregiver integration during discharge planning for older adults to reduce resource use: a meta-analysis. $J$ Am Geriatr Soc. 2017;65(8):1748-1755. doi:10.1111/jgs.14873

6. Nordmark S, Zingmark K, Lindberg I. Process evaluation of discharge planning implementation in healthcare using normalization process theory. BMC Med Inform Decis Mak. 2016;16(1):48. doi:10.1186/s12911-016-0285-4

7. Fox MT, Persaud M, Maimets I, Brooks D, O’Brien K, Tregunno D. Effectiveness of early discharge planning in acutely ill or injured hospitalized older adults: a systematic review and meta-analysis. BMC Geriatr. 2013;13(1):70. doi:10.1186/1471-2318-13-70

8. Socwell CP, Bucci L, Patchell S, Kotowicz E, Edbrooke L, Pope R. Utility of Mayo Clinic's early screen for discharge planning tool for predicting patient length of stay, discharge destination, and readmission risk in an inpatient oncology cohort. Support Care Cancer. 2018;26(11):3843-3849. doi:10.1007/s00520-018-4252-8

9. Mandell LA, Wunderink RG, Anzueto A, et al. Infectious diseases society of America/American thoracic society consensus guidelines on the management of community-acquired pneumonia in adults. Clin Infect Dis. 2007;44:S27-S72. doi:10.1086/511159

10. Kalil AC, Metersky ML, Klompas M, et al. Management of adults with hospital-acquired and ventilator-associated pneumonia: 2016 clinical practice guidelines by the infectious diseases society of America and the American thoracic society. Clin Infect Dis. 2016;63(5):e61-e111. doi:10.1093/cid/ciw353

11. Fine MJ, Auble TE, Yealy DM, et al. A prediction rule to identify low-risk patients with community-acquired pneumonia. $N$ Engl J Med. 1997;336(4):243-250. doi:10.1056/NEJM199701233360402

12. Charlson M, Pompei P, Ales KL, MacKenzie CR. A new method of classifying prognostic comorbidity in longitudinal studies: development and validation. $J$ Chronic Dis. 1987;40(5):373-383. doi:10.1016/0021-9681(87)90171-8

13. Austin PC. Balance diagnostics for comparing the distribution of baseline covariates between treatment groups in propensity-score matched samples. Statist Med. 2009;28(25):3083-3107. doi:10.1002/sim.3697.

14. Zurlo A, Zuliani G. Management of care transition and hospital discharge. Aging Clin Exp Res. 2018;30(3):263-270. doi:10.1007/ s40520-017-0885-6

15. Gonçalves-Bradley DC, Iliffe S, Doll HA, et al. Early discharge hospital at home. Cochrane Database Syst Rev. 2017;6:6. doi:10.1002/14651858.CD000356.pub4

16. Henke RM, Karaca Z, Jackson P, Marder WD, Wong HS. Discharge planning and hospital readmissions. Med Care Res Rev. 2017;74 (3):345-368. doi:10.1177/1077558716647652

17. New PW, McDougall KE, Scroggie CPR. Improving discharge planning communication between hospitals and patients: improving discharge communication. Intern Med J. 2016;46(1):57-62. doi:10.1111/ imj.12919

18. Hetzel-Riggin MD, Swords BA, Tuang HL, Deck JM, Spurgeon NS. Work engagement and resiliency impact the relationship between nursing stress and burnout. Psychol Rep. 2019;123(5):1835-1853. doi:10.1177/0033294119876076

19. D'Sa V, Ploeg J, Fisher A, Akhtar-Danesh N, Peachey G. Potential dangers of nursing overtime in critical care. Nurs Leadersh (Tor Ont). 2018;31(3):48-60. doi:10.12927/cjnl.2018.25677

20. Sir MY, Dundar B, Barker Steege LM, Pasupathy KS. Nurse-patient assignment models considering patient acuity metrics and nurses' perceived workload. $J$ Biomed Inform. 2015;55:237-248. doi:10.1016/j.jbi.2015.04.005

21. Rhew DC, Weingarten SR. Achieving a safe and early discharge for patients with community-acquired pneumonia. Med Clin North Am. 2001;85(6):1427-1440. doi:10.1016/S0025-7125(05)70389-8 


\section{Publish your work in this journal}

Clinical Interventions in Aging is an international, peer-reviewed journal focusing on evidence-based reports on the value or lack thereof of treatments intended to prevent or delay the onset of maladaptive correlates of aging in human beings. This journal is indexed on PubMed Central, MedLine, CAS, Scopus and the Elsevier
Bibliographic databases. The manuscript management system is completely online and includes a very quick and fair peer-review system, which is all easy to use. Visit http://www.dovepress.com/ testimonials.php to read real quotes from published authors. 